\title{
Nephrogenic diabetes insipidus and intracerebral calcification
}

\author{
O Schofer, R Beetz, K Kruse, C Rascher, C Schütz, J Bohl
}

\begin{abstract}
Three children who presented with two rare conditions, nephrogenic diabetes insipidus and intracerebral calcification, were studied. The lack of evidence for the presence of a metabolic defect other than nephrogenic diabetes insipidus suggests that it can lead to the development of intracerebral calcification. Perhaps the main risk factor is inadequate fluid intake during early infancy.
\end{abstract}

Nephrogenic diabetes insipidus is characterised by unresponsiveness of the distal tubule and the collecting duct to normal or increased concentrations of antidiuretic hormone. The renal concentrating defect may be partial or complete. ${ }^{1-3}$

In the primary, hereditary form of the disease, specific cells in the membrane of the distal convoluted tubule and collecting duct are incapable of increasing their permeability to water in response to the action of antidiuretic hormone. The mode of inheritance of primary nephrogenic diabetes insipidus is believed to be $\mathrm{X}$ linked with a variable expression in girls. ${ }^{1-3}$ Secondary nephrogenic diabetes insipidus may develop in numerous disorders including certain neoplasias, medullary cystic disease, and hypercalcaemia.

In a series of 34941 paediatric skull radiographs, pathological calcification was seen in $293(0 \cdot 84 \%){ }^{4}$ The incidence of pathological intracranial calcification in 18000 paediatric computed tomograms was $1 \cdot 6 \% .^{5}$ Calcification was most often seen in children who had had prenatal infections with Toxoplasma gondii $(22 \%)$ or other inflammatory brain diseases. ${ }^{4-6}$ It was also found in association with, or as a consequence of, tumours of the central nervous

Hospital,

Langenbeckstrasse 1, D-6500 Mainz 1,

Federal Republic

of Germany

O Schofer

R Beetz

University Children's

Hospital, Würzburg

K Kruse

University Children's

Hospital, Heidelberg

W Rascher

Children's Hospital,

Regensburg

C Schütz

Department of

Neuropathology

University of Mainz

J Bohl

Correspondence to:

Dr Schofer.

Accepted 20 March 1990 system, intracranial haemorrhage, and hypoparathyroidism or pseudohypoparathyroidism. 578

We report three children (two boys and one girl) who presented with the combination of nephrogenic diabetes insipidus and massive intracerebral calcification. To our knowledge, the concurrence of primary nephrogenic diabetes insipidus and intracerebral calcification has not been reported before.

\section{Case reports}

CASE 1

A girl was born at full term weighing $3200 \mathrm{~g}$. She was $49 \mathrm{~cm}$ long, and had a head circumference of $34 \mathrm{~cm}$ (45th centile). The pregnancy had been uncomplicated and the family history was unremarkable. According to her paediatrician she had developed normally for the first two to three months, and had then experienced recurrent episodes of dehydration that became gradually more serious and eventually led to her first admission to hospital at the age of 6 months. She presented with hyperosmotic dehydration with dilute urine, and by then was already malnourished and showing neurodevelopmental retardation. Subsequently, frequent episodes of severe dehydration occurred, which were usually precipitated by infection. Clinical examination at 4 years of age showed short stature $(91 \mathrm{~cm}, 8 \mathrm{~cm}$ below the 3 rd centile), normal body weight for height $(13.5 \mathrm{~kg})$, microcephaly $(45.9 \mathrm{~cm}, 1.9 \mathrm{~cm}$ below the $3 \mathrm{rd}$ centile), low set ears, delayed dentition, normal blood pressure, and discrete motor coordination defects with an awkward gait. Her intelligence quotient (IQ) was $40-45$ and did not deteriorate thereafter. Results of laboratory tests are summarised in

\begin{tabular}{|c|c|c|c|}
\hline \multirow[t]{2}{*}{ Variable (reference range) } & \multicolumn{3}{|l|}{ Case No } \\
\hline & 1 & 2 & 3 \\
\hline $\begin{array}{l}\text { Serum: } \\
\text { Sodium }(135-145 \mathrm{mmol} / \mathrm{l}) \\
\text { Chloride }(96-106 \cdot \mathrm{mmol} / \mathrm{l}) \\
\text { Potassium }(3 \cdot 0-4 \cdot 5 \mathrm{mmol} / \mathrm{l}) \\
\text { Calcium }(2 \cdot 0-2 \cdot 5 \mathrm{mmol} / \mathrm{l}) \\
\text { Inorganic phosphate }(1 \cdot 4-2 \cdot 2 \mathrm{mmol} / \mathrm{l}) \\
\text { Osmolality }(280-295 \mathrm{mmol} / \mathrm{kg}) \\
\text { Antidiuretic hormone }(2-4 \mathrm{pg} / \mathrm{ml})^{*} \\
\text { Parathyroid hormone }(30-90 \mathrm{pmol} / \mathrm{l})\end{array}$ & $\begin{array}{l}144-173 \\
108-121 \\
1 \cdot 8-3 \cdot 6 \\
2 \cdot 3-2 \cdot 5 \\
1 \cdot 4-1 \cdot 5 \\
306-320 \\
51 \cdot 1 \\
53\end{array}$ & $\begin{array}{l}139-160 \\
108-120 \\
3 \cdot 2-4 \cdot 4 \\
2 \cdot 3 \\
1 \cdot 6-2 \cdot 4 \\
297-316 \\
10 \cdot 7 \\
60\end{array}$ & $\begin{array}{l}142-165 \\
108-121 \\
2 \cdot 9-4 \cdot 2 \\
2 \cdot 2 \\
1 \cdot 5-2 \cdot 2 \\
285-322 \\
45 \cdot 6 \\
44\end{array}$ \\
\hline $\begin{array}{l}\text { Urine: } \\
\text { Osmolality }(120-800 \mathrm{mmol} / \mathrm{kg}) \\
\text { Osmolality after antidiuretic hormone }(>150 \text { of baseline }) \\
\text { Cyclic AMP }(200-450 \mu \mathrm{mol} / 24 \mathrm{~h} \text { or } 2-6 \mathrm{nmol} / 100 \mathrm{ml}+) \\
\text { Glomerular filtration rate (as creatinine clearance) }\left(80-120 \mathrm{ml} / \mathrm{min} / 1 \cdot 73 \mathrm{~m}^{2}\right) \\
\text { Tubular reabsorption of phosphate }(80-97 \%)\end{array}$ & $\begin{array}{l}120-233 \\
160(105 \%) \\
\text { Not tested } \\
80 \\
88 \%\end{array}$ & $\begin{array}{c}72-92 \\
\text { Not tested } \\
1340(24 \mathrm{~h}) \\
106 \\
94 \%\end{array}$ & $\begin{array}{l}132 \\
\text { Not tested } \\
5 \cdot 3 \dagger \\
113 \\
86 \%\end{array}$ \\
\hline
\end{tabular}

${ }^{*}$ Measured at the following serum osmolalities: $306 \mathrm{mmol} / \mathrm{kg}$ in case $1,297 \mathrm{mmol} / \mathrm{kg}$ in case 2 , and $287 \mathrm{mmol} / \mathrm{kg}$ in case 3 . +Cyclic AMP is measured as $\mathrm{nmol} / 100 \mathrm{ml}$ glomerular filtration rate as creatinine clearance. 

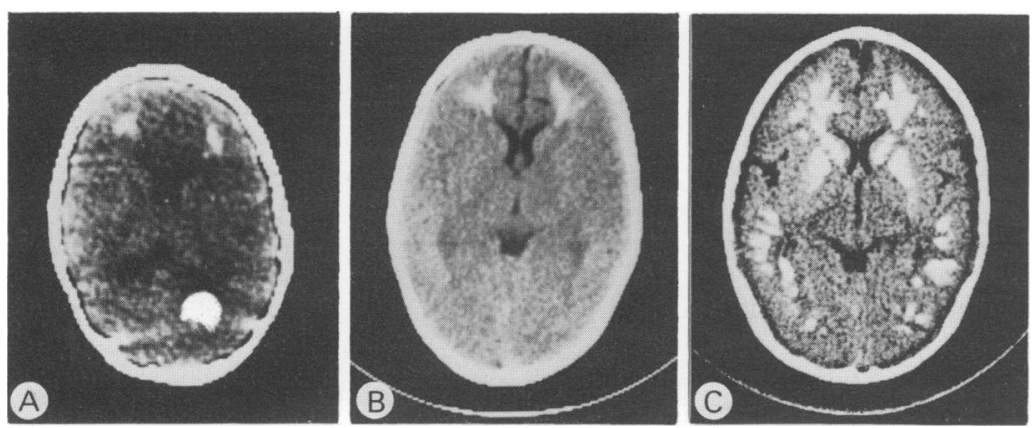

Figure 1 Cranial computed tomography showing: $(A)$ symmetrical calcification predominantly in the frontal white matter (case 1$),(B)$ symmetric calcification mainly in the caudate nucleus, lentiform nucleus, and the frontal white matter (case 2$)$; and $(C)$ massive but non-progressive calcification particularly in the white matter of the frontal, parietal, and occipital lobes (case 3).
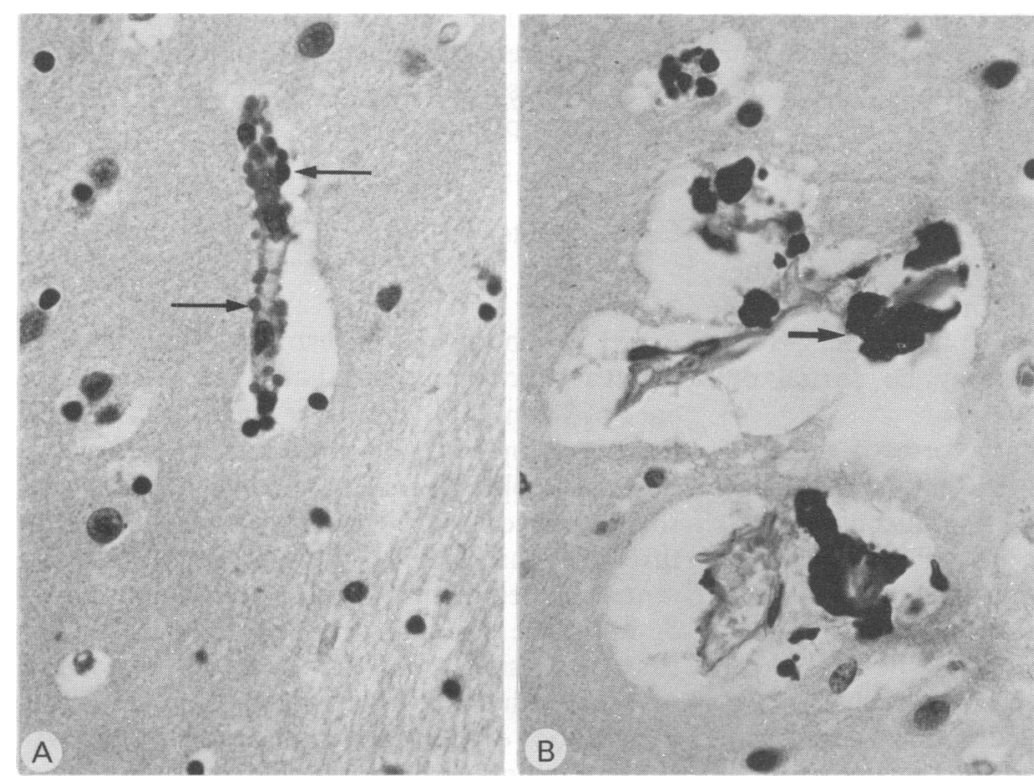

Figure 2 Sections of the rostral basal ganglia (caudate nucleus and putamen stained with periodic acid Schiff at a magnification of 160 ) showing: $(A)$ fine granulated perivascular calcification-the wall and lumen of the vessel as well as the nuclei of the endothelial cells are preserved; and $(B)$ : large, confluencing perivascular deposits of calcium-the wall of the included vessel is destroyed in most parts (case 1).

the table. Renal morphology on ultrasound scanning, chromosome analysis, and skeletal radiographs were normal. At the age of 4 years she developed seizures, and symmetric intracerebral calcification was found on computed tomography, predominantly within the frontal white matter (fig 1).

She died when she was $8 \cdot 8$ years old of septicaemia with severe electrolyte disturbances, and at necropsy there were signs of generalised bacterial infection. Her kidneys contained a few small tubular cysts within the cortex, but no calcification. Disseminated intracerebral perivascular and pericapillar calcification were found in the cortex and the basal ganglia (fig 2). Neuronal cells were unaffected but there were discrete signs of demyelination as well as reactive gliosis.

CASE 2

A boy was born without complications after a normal pregnancy. His mother had a decreased renal concentrating capability when deprived of water, but there was no other family history of renal disease, particularly nephrogenic diabetes insipidus, or other congenital diseases, movement disorders, or consanguinity. He was first admitted to hospital at the age of 4 weeks because of hypertonic dehydration during an upper respiratory tract infection. The diagnosis of inherited primary nephrogenic diabetes insipidus was eventually confirmed by combined mannitol challenge and vasopressin test. Possible secondary nephrogenic diabetes insipidus was excluded. His daily urine output when receiving maintenance treatment with either frusemide and spironolactone, or hydrochlorothiazide and spironolactone, was 21 at the end of his first year, 31 when he was 2 years old, and 4-5 1 at the age of 8 years. After infancy episodes of dehydration occurred only during febrile infections. At the age of 4 years he had a seizure. Two years later, cranial computed tomography showed symmetric intracerebral calcification predominantly within the caudate nucleus, the lentiform nucleus, and the frontal white matter (fig 1). His mental and motor development was retarded by $2-2 \cdot 5$ years at that time, but he was making progress.

When last seen at the age of 8 years, he was in good health with increased body weight and improved psychomotor development. His blood pressure was normal throughout. Results of laboratory tests are summarised in the table. The kidneys showed no evidence of calcification; there were no skeletal abnormalities, and no evidence of prenatal or postnatal infection with $T$ gondii or cytomegalovirus was found.

\section{CASE 3}

A boy was born at full term after an uncomplicated pregnancy and delivery. He weighed 3600 $\mathrm{g}$ at birth, and was $51 \mathrm{~cm}$ long. The family history was uneventful. At the age of 7 months he was admitted to hospital because of recurrent vomiting, constipation, intermittent fever, failure to thrive, growth retardation, irritability, and convulsions. He was severely malnourished being $64 \mathrm{~cm}$ long ( $4 \mathrm{~cm}$ below the 3rd centile), weighing $6.5 \mathrm{~kg}$ (3rd centile), and with a head circumference of $41 \mathrm{~cm}(0.5 \mathrm{~cm}$ below the $3 \mathrm{rd}$ centile). Nephrogenic diabetes insipidus was suspected because of persistent hypotonic urine in spite of increased serum sodium concentration and osmolality.

Results of laboratory tests are summarised in the table. The diagnosis of primary nephrogenic diabetes insipidus was established by increased serum concentrations of antidiuretic hormone and failure of the adequately hydrated patient to increase his urinary osmolality in response to repeated nasal administration of desmopressin acetate (DDAVP). Other disorders with secondary resistance to antidiuretic hormone were excluded. The extracellular calcium and phosphate metabolism, which was investigated at 20 months, was normal; impairment of the kidney response to parathyroid hormone was excluded. Treatment with a restricted protein and salt intake and hydrochlorothiazide $(2 \mathrm{mg} / \mathrm{kg} /$ day $)$ resulted in pronounced improvement of water 
and electrolyte balance, growth, weight gain, and psychomotor development.

Computed tomography at 7 and 14 months showed massive, but non-progressive, brain calcification, particularly in the white matter of the frontal, parietal, and occipital lobes (fig 1). Serological investigations gave no evidence of prenatal infection with $T$ gondii, cytomegalovirus, rubella, herpes simplex virus, or Treponema pallidum.

\section{Discussion}

All three children had nephrogenic diabetes insipidus and intracerebral calcification. The association of two such rare conditions suggests that there may be a common pathogenesis.

Diseases causing secondary nephrogenic diabetes insipidus - such as medullary cystic kidney disease, chronic obstructive uropathy, nephrocalcinosis, hypercalciuria, polycystic kidneys, chronic severe hypokalaemia, and malignant tumours that can be associated with nephrogenic diabetes insipidus (for example, oat cell carcinoma of the lung)-were excluded. ${ }^{1-3}$ Nephrogenic diabetes insipidus was therefore classified as a primary lack of tubular response to antidiuretic hormone.

Underlying disorders associated with intracerebral calcification are mainly prenatal or postnatal infections with $T$ gondii or cytomegalovirus, ${ }^{46}$ endocrine abnormalities such as all forms of hypoparathyroidism and pseudohypoparathyroidism, ${ }^{7-9}$ toxic or hypoxic damage to the central nervous system, ${ }^{10-12}$ and some congenital disorders with a yet unknown metabolic cause. ${ }^{13-15} \mathrm{Within}$ this last group of disorders, Fahr-Volhard disease,${ }^{14} 16$ oculocraniosomatic disease, ${ }^{15} 17$ and Cockayne's syndrome $^{13}$ have to be principally considered. Obviously hypoparathyroidism would be the most attractive choice of underlying pathology because both main symptoms (nephrogenic diabetes insipidus and intracerebral calcification) could be explained, but this was ruled out by the finding of normal parathyroid hormone and calcium concentrations in all patients. Evidence against pseudohypoparathyroidism and pseudopseudohypoparathyroidism was based on the normal concentrations of calcium and phosphate in serum and urine, the absence of renal calcification, and the absence of skeletal abnormalities. ${ }^{7-9}$ Thus no underlying pathology other than nephrogenic diabetes insipidus could be found to explain the intracerebral calcification. All patients had, however, experienced recurrent episodes of severe dehydration due to the relative or absolute unresponsiveness of their renal tubules to antidiuretic hormone.

To our knowledge intracerebral calcification has not previously been reported as a consequence or possible complication of nephrogenic diabetes insipidus. ${ }^{1-3}$ The distribution of the calcification (often lining small vessels) found at necropsy (case 1) lends some weight to the following hypothetical sequence: nephrogenic diabetes insipidus leads to recurrent severe hyperosmolar dehydration that damages endothelial and other cells. This exposes material with nucleating properties (for example, mitochondria or collagen) to calcium and phosphate in solution and perhaps alters calcification inhibitors such as glycosaminoglycans or inorganic pyrophosphate. ${ }^{18}$ As a consequence, calcium phosphate and other such substances are deposited particularly within or around the walls of small vessels, or both. ${ }^{18}$

From the clinical point of view it could be worthwhile to investigate a larger group of patients with nephrogenic diabetes insipidus and severe episodes of dehydration during early infancy, to find out the incidence of intracerebral calcification.

1 Culpepper RM, Hebert SC, Andreoli TE. Nephrogenic diabetes insipidus. In: Stanbury JB, Wyngaarden JB diabetes insipidus. In: Stanbury JB, Wyngaarden JB,
Fredrickson DS, Goldstein JL, Brown MS, eds. The Fredrickson DS, Goldstein JL, Brown MS, eds. The metabolic basis of inherited

2 Kaplan SA. Nephrogenic diabetes insipidus. In: Holliday MA, Barratt TM, Vernier RL, eds. Pediatric nephrology. 2nd Ed. Baltimore: Williams and Wilkins, 1987:623-5.

3 Stern P. Nephrogenic defects of urinary concentration. In Edelmann CM, ed. Diseases of the kidney. Vol II. Boston Little, Brown and Company, 1978:987-95.

4 Willich E, Sellier W, Weigel W. Die intrakraniellen Verkalkungen des Kindesalters. Fortschrifte auf dem Gebiete der Röntgenstrahlen 1972;116:735-50.

5 Kendall B, Cavanagh N. Intracranial calcification in paediatric computed tomography. Neuroradiology 1986;28:324-30.

6 Feigin RD, Cherry JD, eds. Textbook of pediatric infections diseases. Philadelphia: WB Saunders, 1981 .

Drezner MK Neelon FA. Pund Szelon FA. Pseudohypoparathyroidism. In: Stanbury JB, Wyngaarden JB, Fredrickson DS, Goldstein 5th Ed. New York: McGraw-Hill, 1983:1508-27.

8 Camp JD. Symmetrical calcification of cerebral basal ganglia its roentgenologic significance in diagnosis of parathyroid insufficiency. Radiology 1947;49:568-77.

9 Steinbach $\mathrm{HL}$, Young DA. The roentgen appearance of pseudohypoparathyroidism (PH) and pseudopseudohypoparathyroidism (PPH). Differentiation from other syndromes associated with short metacarpals, metatarsals, and phalanges. AfR 1966;97:49-66.

10 Illum F. Calcification of the basal ganglia following carbon monoxide poisoning. Neuroradiology 1980;19:213-4.

11 Numaguchi Y, Hoffman JC, Sones PJ. Basal ganglia calcification as a late radiation effect. $A \mathcal{F} R$ 1975;123:27-30.

12 Peylan-Ramu N, Poplack DG, Blei CL, Herdt JR, Vermess M, Di Chiro G. Computer assisted tomography in methrotrexate encephalopathy. F Comput Assist Tomogr 1977;1: 216-21.

13 Cockayne EA. Dwarfism with retinal atrophy and deafness. Arch Dis Child 1946;21:52-4.

14 Fahr T. Idiopathische Verkalkungen der Hirngefäße. Zentralbl Allg Pathol 1930;50:129-33.

15 Kearns TP, Sayre GP. Retinitis pigmentosa, external ophthalmoplegia, and complete heart block. Arch Ophthal mol 1958;60:280-9.

16 Kazis AD. Contribution of CT scan to the diagnosis of Fahr's syndrome. Acta Neurol Scand 1985;71:206-11.

17 Seigel RS, Seeger JF, Gabrielson TO, Allen RJ. Computed tomography in oculocraniosomatic disease (Kearns-Sayre syndrome). Radiology 1979;130:159-64.

18 Russel RGG, Caswell AM, Hearn PR, Sharrad RM. Calcium in mineralized tissues and pathological calcification. $B$ Med Bull 1986;42:435-46. 